\title{
Avaliação Pré-Cirúrgica de Pacientes com Epilepsia Parcial Refratária: Papel da Interação entre Avanços Tecnológicos e Avanços Conceituais
}

\author{
André Palmini , Jaderson Costa da Costa**, \\ Maria Elisa Calcagnotto*** \& José Victor Longo Martinez***
}

\begin{abstract}
RESUMO
Grandes avanços tecnológicos tem ocorrido nas técnicas de avaliação pré-cirúrgica de pacientes com epilepsia refratária. Com o intuito de delimitar a zona epileptogênica (i.e. a região cortical duja remoção é necessária e suficiente para o controle das crises), deve-se saber interpretar e hierarquizar os dados obtidos na investigação, já que estes nem sempre são completamente convergentes. Isso faz a necessidade de que se avance também conceitualmente, pari pasu com as inovações tecnológicas. Este artigo faz uma revisão sobre as técnicas e conceitos que permitem delimitar esta zona, discute a necessidade de obter um diagnóstico tri-axial (topográfico, etiológico e sindrômico) e comenta sobre novos conceitos concernentes a epilepsia focal.
\end{abstract}

\section{UNITERMOS}

Avaliação pré-operatória, epilepsia refratária, resultados cirúrgicos.
Neurologista e neurofisiologista clínico, professor assistente de neurologia da Faculdade de Medicina da PUCRS, diretor científico do Programa de Cirurgia da Epilepsia do Hospital São Lucas da PUCRS.

* Neurologista e neurofisiologista clínico, professor titular de neurologia da Faculdade de Medicina da PUCRS, diretor médico do Programa de Cirurgia da Epilepsia do Hospital São Lucas da PUCRS.

*** Neurologistas, alunos do Curso de Extensão em Neurociências - Epilepsia, Faculdade de Medicina e Hospital São Lucas da PUCRS.
A aceitação cada vez mais unânime do tratamento cirúrgico como alternativa terapêutica em pacientes epiléticos com crises refratárias naturalmente tem aumentado a responsabilidade dos centros especializados na avaliação pré-operatória destes pacientes. Isso tem contribuído para um progressivo refinamento do processo de seleção, almejando a obtenção de resultados cada vez melhores para um número crescente de pacientes com uma grande variedade de síndromes epiléticas. Tanto a nível nacional quanto nos principais centros no exterior vive-se um momento misto de euforia e reflexão. Euforia pela disponibilidade crescente de um armamentário tecnológico sofisticado, que permite a identificação cada vez mais acurada de lesões estruturais e de disfunções neurofisiológicas associadas à epilepsia; reflexão pela necessidade de compreender-se melhor o significado e a relevância de uma série de informações novas aportadas justamente por estes avanços nas técnicas de avaliação.

Recentemente, uma série de centros especializados em cirurgia da epilepsia têm relatado os resultados do tratamento cirúrgico de pacientes com crises refratárias no contexto de diversas formas de epilepsia, após longos períodos de observação pós-operatória ${ }^{1,3,6,11,34}$. Em contraste com os resultados relatados quando limita-se a observação pós-operatória a períodos mais curtos, os estudos com 'follow up' prolongado mostram que o controle das crises após a cirurgia varia de forma dinâmica em todas as síndromes epiléticas suscetíveis ao tratamento cirúrgico. Muito embora um confortável grau de previsibilidade quanto aos resultados sem dúvida exista, muitos pacientes aparentemente com situações homogêneas, submetidos a cirurgias semelhantes, apresentam evolução distinta, especialmente após vários anos de seguimento. A principal constatação a partir destes estudos é que ainda há muito a ser compreendido a respeito da neurobiologia das epilepsias, para que se obtenham resultados cada vez melhores e mais uniformes com o 
tratamento cirúrgico. Como a tecnologia para tal tem se tornado cada vez mais disponível ${ }^{7,10,12}$, surge o desafio para que possamos, utilizando estas novas técnicas, avançar conceitualmente.

Ao longo dos anos 80, os novos sistemas de monitorização prolongada do EEG por telemetria, as correlações videoeletrencefalográficas, o emprego crescente de eletrodos intracranianos para a identificação da área de origem das crises e o advento da neuroimagem por ressonância magnética (RM) formaram uma base de dados que levou a indiscutíveis avanços na conceitualização dos diversos níveis de disfunção associados às epilepsias de difícil controle. Talvez a melhor formalização destes avanços tenha sido a definição e a demonstração das formas de inter-relação entre zona irritativa, zona de origem das crises, zona sintomatogênica, zona de disfunção cortical e zona de substrato lesional ${ }^{15}$. A partir destes avanços conceituais passou-se a conceber a avaliação pré-operatória de pacientes com epilepsia de difícil controle como a aplicação de um conjunto de métodos independentes com a finalidade de identificar estas diversas 'zonas' de disfunção. Tal identificação permite que se localize o que se convencionou denominar 'zona epileptogênica', definida como a porção de córtex cerebral cuja ressecção é necessária e suficiente para controlar as crises habituais do paciente ${ }^{15}$.

Sem dúvida, a interação entre avanços tecnológicos e conceituais descrita acima tem tido um grande impacto na condução da investigação pré-operatória de pacientes com epilepsia refratária. Novas estratégias cirúrgicas foram delineadas e os resultados como um todo melhoraram muito, quando comparados com aqueles obtidos em décadas precedentes ${ }^{11}$. Entretanto, um significativo contingente de pacientes persiste desafiando os epileptologistas, seja no que tange à localização da zona epileptogênica quanto à obtenção de resultados ainda mais satisfatórios. Tais desafios somente serão enfrentados a contento com um novo ciclo de avanços, tanto tecnológicos quanto conceituais. Este ciclo já começou e sua análise constitui-se na motivação maior desta revisão.

O presente artigo inicia com uma breve revisão do armamentário semiológico e tecnológico disponível para que se localize as diversas áreas ou zonas de disfunção cortical associadas à epilepsia. Prossegue definindo estas áreas e analisando os diversos graus de convergência espacial que podem ser observados entre as mesmas. Depois, o artigo discute a respeito da propriedade de obter-se um diagnóstico tri-axial em epileptologia - não apenas topográfico, mas também etiológico e sindrômico - e descreve exemplos recentes de avanços conceituais com implicações na avaliação pré-cirúrgica, nas estratégias operatórias e nas previsões prognósticas. Por fim, conceitos de epilepsia focal são desafiados à luz de avanços tecnológicos recentes, e o papel destes avanços na previsão mais acurada dos resultados cirúrgicos em pacientes com a forma mais comum de epilepsia refratária - epilepsia têmporo-límbica associada à esclerose hipocampal - é então hipotetizado.

Apesar dos vários aspectos eminentemente técnicos que serão apresentados, a mensagem que pretendemos deixar é que a condução do processo de avaliação préoperatória e a tomada de decisões em pacientes com epilepsia refratária envolve um conhecimento que extrapola a mera 'soma algébrica' de evidências de localização da disfunção epileptogênica. A experiência acumulada mostra que decisões acertadas somente são tomadas a partir de uma análise que combine a história individual da epilepsia de cada paciente com a história natural de cada uma das diversas síndromes epiléticas suscetíveis ao tratamento cirúrgico. Somente a partir deste ponto é que os resultados objetivos da avaliação pré-operatória são integrados para responder à questão fundamental do quanto um procedimento cirúrgico poderá interferir positivamente no processo.

\section{INSTRUMENTOS UTILIZADOS NA AVALIAÇÃO PRÉ-OPERATÓRIA}

Com o intuito de localizar-se a extensão de tecido cortical epileptogênico responsável pelas crises e cuja ressecção é assim necessária e suficiente para controlálas de forma consistente e duradoura ('zona epileptogênica'), lançamos mão de uma série de instrumentos. O primeiro é a palavra. Uma história clínica detalhada freqüentemente fornece informações importantes que podem sugerir o sítio de origem das crises, a provável etiologia da alteração cortical subjacente e o impacto funcional das crises na vida do paciente. Assim, a presença (ou ausência) de um ou mais tipos de aura pode ser a primeira indicação da zona epileptogênica $^{21}$. Aproximadamente 85 a $90 \%$ dos pacientes com crises de origem nas estruturas mesiais do lobo temporal, mas apenas $60 \%$ daqueles com crises originadas nos lobos frontais relatam algum tipo de aura $^{21}$. Além disso, a vasta maioria das auras associadas a crises de origem têmporo-límbica são sensações nas esferas vegetativa (mal-estar epigástrico, palpitações) e experiencial (medo súbito, imotivado, déjà vu, déjà vécu, pensamento forçado, alucinações olfativas e gustatórias). Embora não-exclusivas de crises originadas 
nas regiões temporais mesiais, sua ocorrência em crises com origem confirmada em estruturas extratemporais é bastante incomum ${ }^{21}$. Por outro lado, quando apresentam auras, pacientes com zonas epileptogênicas frontais relatam geralmente sensações cefálicas pouco definidas, tonturas, ou até mesmo sintomas sômato-sensoriais como parestesias ou choques, localizados a uma região corporal específica ou difusos. Neste último contexto, tais auras, especialmente quando unilaterais, são freqüentemente compartilhadas por crises de início no córtex parietal sômato-sensitivo. Por fim, auras visuais elementares, ou seja, visão de luzes piscando, flashes, círculos coloridos, ou ainda cegueira súbita têm alta correlação com crises originadas no córtex visual primário nas regiões occipitais mesiais. Efetivamente, aproximadamente $80 \%$ dos pacientes com epilepsia occipital têm suas crises iniciadas por alguma sensação visual dita elementar ${ }^{27}$. A mensagem aqui é clara: auras podem fornecer informações importantes e devem ser pesquisadas detalhadamente, mesmo que se tenha de ir listando-as, uma a uma, para o paciente. É interessante como um porcentual significativo de pacientes que efetivamente iniciam suas crises por algum tipo de aura não as relatam espontaneamente, mas sim somente quando especificamente questionados.

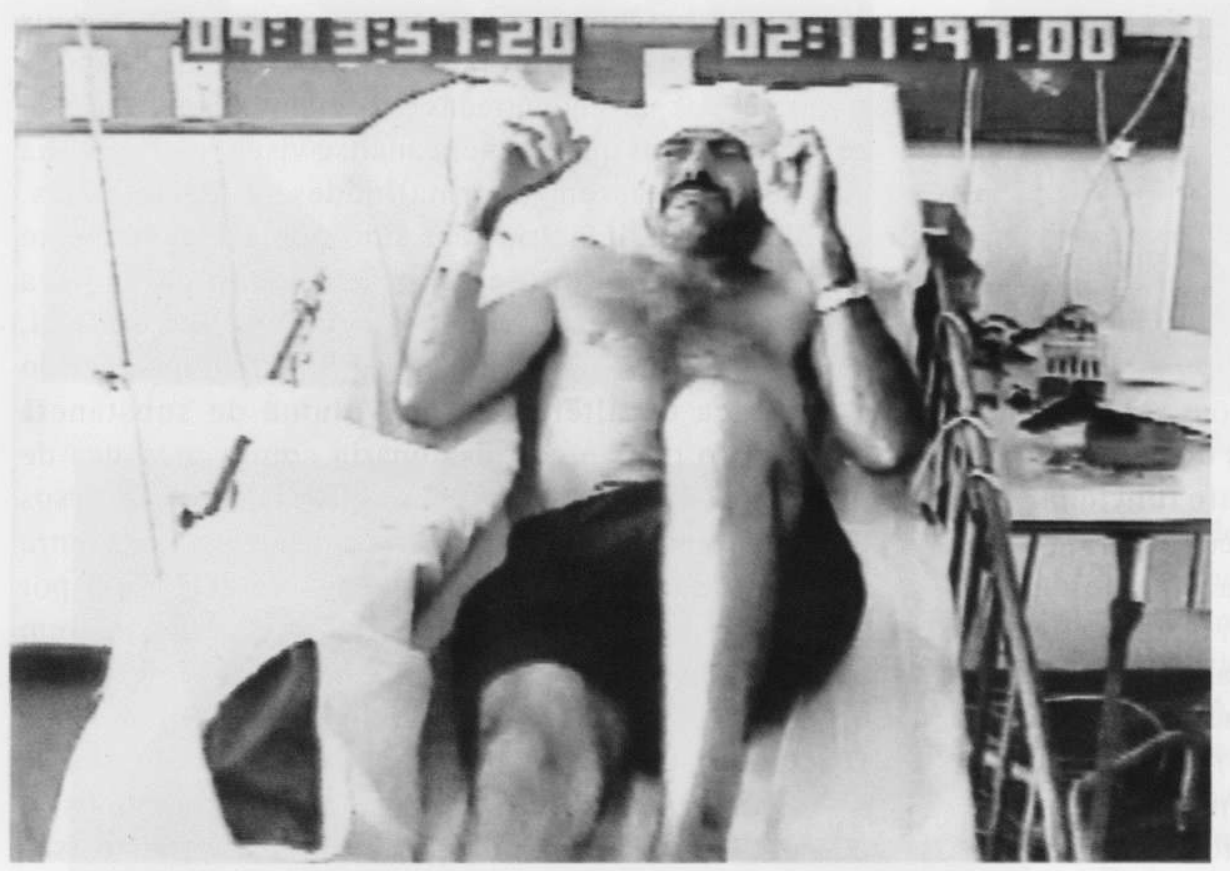

FIGURA 1

Imagem fotografada durante videomonitorização em paciente com crises de origem comprovada em região parietal $\mathrm{D}$ associada à cavernoma nesta área. Observe manifestações inespecíficas praticamente sugestivas de propagação da atividade epileptógena.
Além da natureza da aura, a obtenção de informações (que deverão ser confirmadas posteriormente através da monitorização ictal por vídeo) sobre os eventos que se seguem à aura também têm importante papel localizatório. Automatismos sutis, em geral oro-mastigatórios e gestuais são comuns em crises de origem têmporo-límbica, enquanto automatismos grosseiros, que envolvem movimentos irregulares, amplos, das 4 extremidades e da pelve, por vezes mimetizando movimentos característicos de natação, pulos ou danças são observados em algumas crises de origem frontal, em outras áreas da neocórtex, por vezes posturas motoras inespecíficas são observadas ${ }^{18}$ (figura 1).

Ainda dentro da anamnese, é fundamental que se procure ter uma idéia, mesmo que inicial e aproximada, da etiologia da alteração cortical responsável pela epilepsia. Muito embora estudos sofisticados de imagem costumem ter a palavra final a este respeito, a história clínica permite inferências e hipóteses que deverão ser testadas a posteriori. Alguns exemplos pungentes são uma história de convulsões febris prolongadas e sua possível associação com esclerose hipocampal ${ }^{30}$, a existência de uma história de doença febril associada a distúrbio da consciência (às vezes coma) que pode sugerir uma encefalite e associar-se com epilepsia parcial multifocal de difícil controle, história de traumatismo craniano com perda de consciência, que associa-se a regiões glióticas e assim por diante.

Por fim, a anamnese com o paciente e sua família fornecem informações relevantes que permitem determinar a adequação do tratamento farmacológico ao qual um determinado paciente tem sido submetido, seu nível de 'compliance' e, acima de tudo, o impacto funcional das crises na sua vida. Estes 3 últimos aspectos definem a epilepsia como refratária e estimulam a consideração do paciente como um candidato à cirurgia da epilepsia.

A seguir, deve-se lançar mão do exame físico neurológico. Sua função principal no contexto da avaliação pré-operatória é determinar a existência e a severidade de alterações motoras (piramidais) ou visuais (campo visual). Esta informação tem duas finalidades 
importantes. A primeira é identificar a região cortical associada à alteração neurológica como disfuncionada e, assim, com chances de estar ligada à lesão cortical responsável pela epilepsia; em outras palavras, uma finalidade localizatória. A segunda finalidade é determinar a extensão já existente de déficit motor ou visual. Isso será de extrema relevância para a definição de eventuais estratégias cirúrgicas que envolvam a perspectiva de ressecções de áreas corticais associadas a funções motoras ou visuais. Assim, uma proposta de hemisferectomia para um paciente com uma patologia cortical unilateral extensa como a hemimegalencefalia ${ }^{2,31,35}$ e que já apresenta um severo déficit motor contralateral, é muito mais realista do que se este mesmo paciente apresenta apenas um déficit motor leve.

Após estes passos clínicos iniciais, passamos para os instrumentos de avaliação neurofisiológica. Aqui entram em jogo os sistemas de monitorização prolongada por telemetria, com o registro simultâneo do EEG e das crises do paciente. Estes sistemas estão se sofisticando cada vez mais, com a introdução de 'softwares' que reconhecem automaticamente descargas epileptógenas interictais e crises eletrográficas, selecionando estes trechos do traçado para revisão posterior. Estes sistemas permitem o emprego de um número bem maior de eletrodos (32 ou 64 canais estão disponíveis), além da reformatação imediata das montagens para responder a perguntas específicas de localização de eventos epileptogênicos. Estas propriedades, somadas à correlação simultânea dos eventos eletrográficos com o comportamento do paciente observado através de vídeo, têm aumentado cada vez mais a acurácia para a identificação das regiões corticais relevantes para a epilepsia de cada paciente. O papel adicional representado pela utilização de eletrodos intracranianos em casos selecionados será visto em seções subseqüentes.

Chega-se então aos instrumentos de avaliação por neuroimagem, tanto estrutural quanto funcional. Não há dúvidas de que neste aspecto concentram-se os principais avanços tecnológicos na metodologia da avaliação pré-operatória em epilepsia que, como sugeri na introdução, estão sendo integrados em avanços também conceituais. A grande virada em termos de neuroimagem iniciou-se na segunda metade da década de 80 com o salto de qualidade na neuroimagem estrutural representado pelo advento da ressonância magnética (RM) e com ela a possibilidade de identificação de alterações estruturais antes apenas inferidas ou encontradas ao acaso durante a análise histopatológica do tecido cortical excisado ${ }^{13}$. Em especial, a RM trouxe a possibilidade de identificação 'in vivo' de esclerose hipocampal ${ }^{4}$ - o principal substrato patológico subjacente à epilepsia temporal lesões displásicas localizadas ${ }^{19}$, além de gliomas de crescimento lento e cavernomas de pequenas dimensões (figura 2: a, b, c, d). Tal possibilidade de identificação inaugurou a era de estudos sobre as relações topográficas entre lesão epileptogênica e zona epileptogênica, levando não apenas aos avanços conceituais a que nos referimos na introdução ${ }^{15}$, como também ao delineamento de estratégias cirúrgicas específicas para lidar com os diversos substratos patológicos ligados à epilepsia refratária ${ }^{23}$.

Os anos 90 têm assistido a um verdadeiro 'boom' no aperfeiçoamento e desenvolvimento de novas técnicas de RM. Não apenas a resolução da imagem melhorou muito com os aparelhos de 1.5 Tesla, como entraram na arena clínica os estudos de volumetria hipocampal e da relaxometria em $\mathrm{T} 2{ }^{7,14}$. Em poucas palavras, enquanto que o estudo de imagem por RM fornece uma idéia qualitativa dos hipocampos, tanto em termos de tamanho quanto de sinal, tanto a volumetria por RM e a relaxometria em $\mathrm{T} 2$ fornecem dados quantitativos. A volumetria, através do delineamento cuidadoso da área ocupada pelos hipocampos (e, em alguns casos, também pela amídala) em cada um de uma seqüência consecutiva de 64 ou 128 cortes coronais com pouco mais de $1 \mathrm{~mm}$ de espessura, permite que se calcule o volume dos hipocampos. Quando comparados entre si e com os dados de uma população-controle, alterações significativas são encontradas em um porcentual variável de pacientes nos quais a mera análise visual não permitia que se detectassem anormalidades ou assimetrias. Técnicas de volumetria têm sido ainda recentemente aplicadas para regiões extra-hipocampais, para quantificar o volume de substância cinzenta cortical. Principalmente o grupo de Queen Square tem sugerido a presença de alterações no volume de substância cinzenta (o que se correlacionaria com a presença de alterações displásicas microscópicas?!) em diversos pacientes com epilepsia refratária em que nenhuma outra lesão estrutural foi identificada ${ }^{32}$. A relaxometria por T2 aponta na mesma direção, apenas que levando em conta não as dimensões mas o sinal intra-hipocampal. $\mathrm{Na}$ esclerose hipocampal, além da atrofia em si - que vai refletir-se por alterações de dimensão - observa-se a substituição de tecido neuronal por células gliais, o que modifica o sinal intra-hipocampal ${ }^{4}$. Novamente, isso pode ser identificado qualitativamente, em imagens ponderadas em $\mathrm{T} 1$ e, especialmente em T2, ou quantitativamente, através de uma técnica que permite quantificar as alterações em T2 naquele tecido ${ }^{14}$.

No que tange à neuroimagem funcional, os avanços recentes não são menos significativos. Além de 


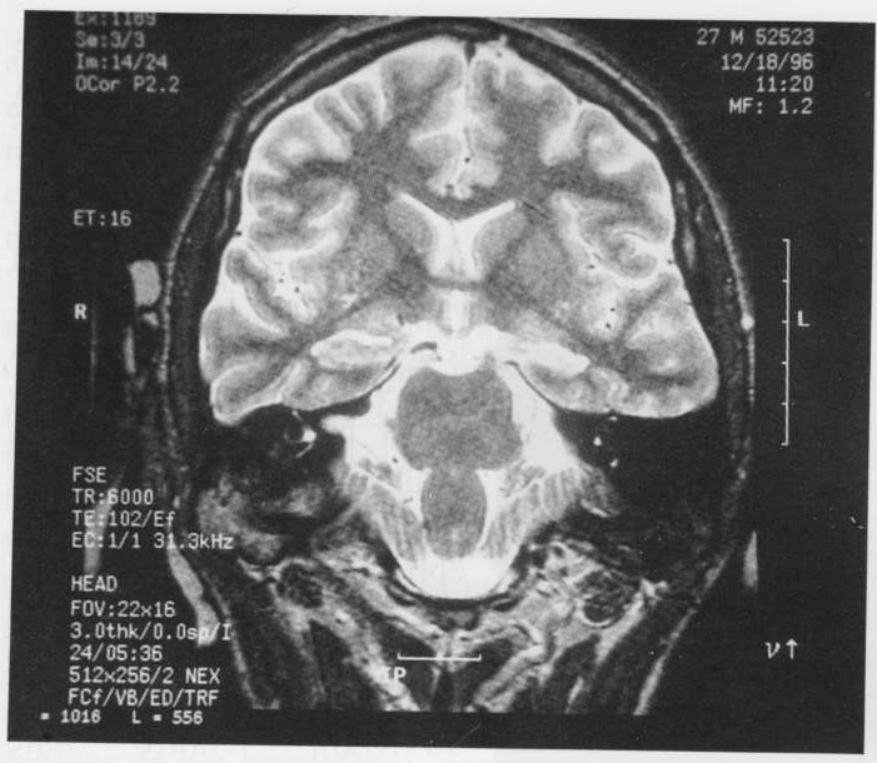

$\stackrel{*}{*}$

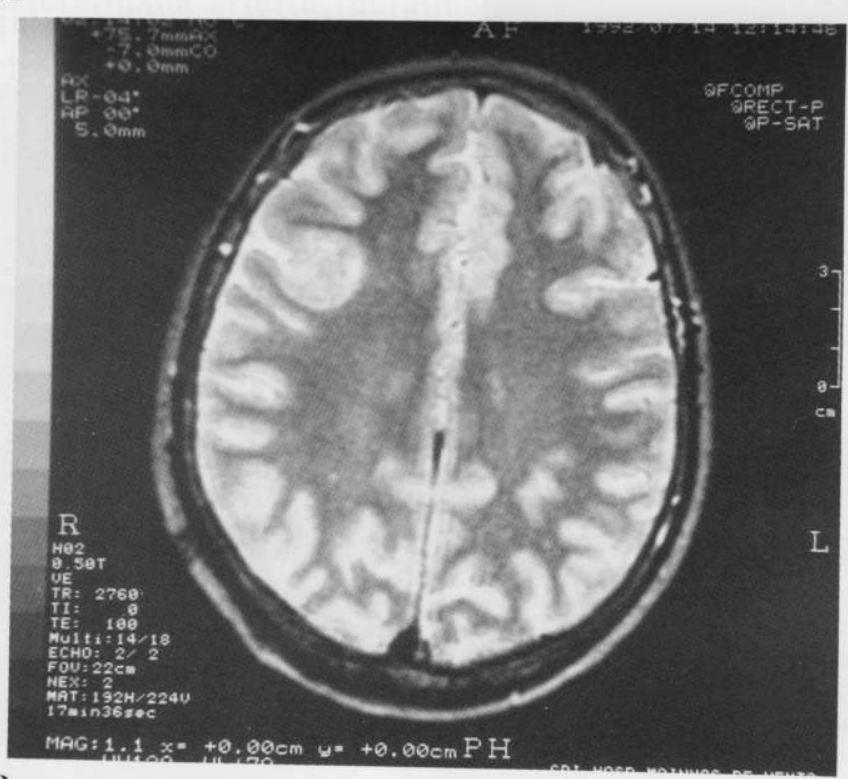

B

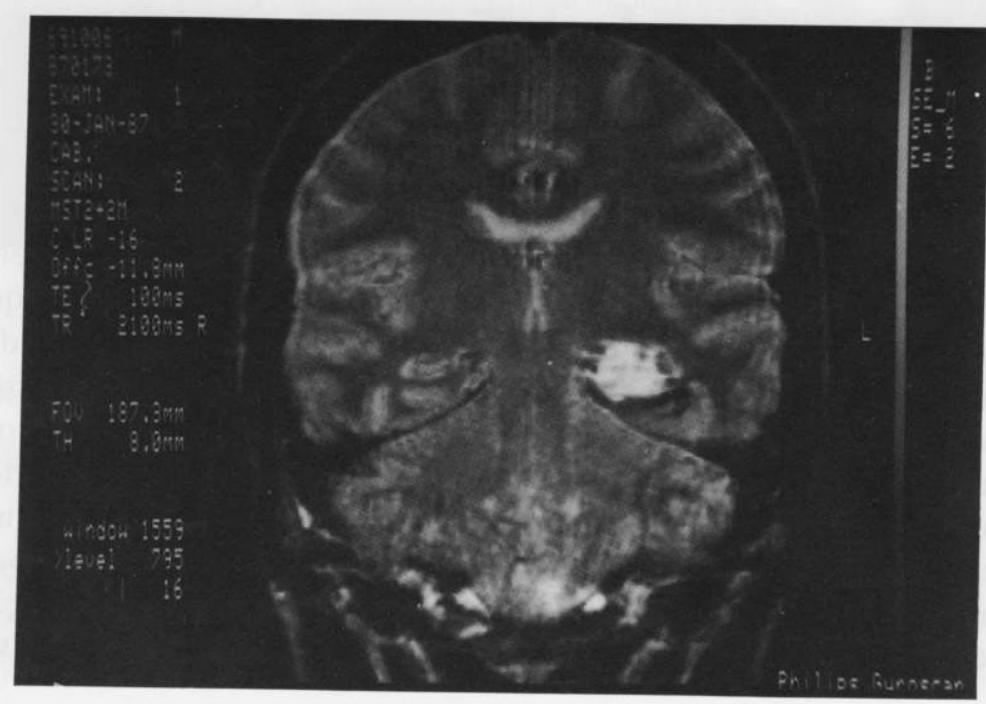

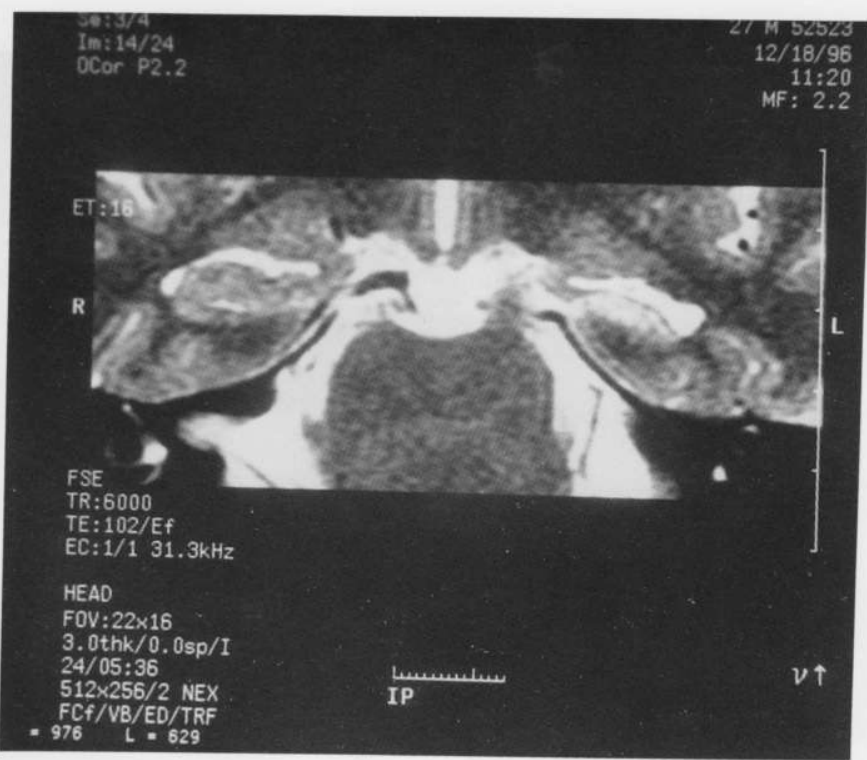

A

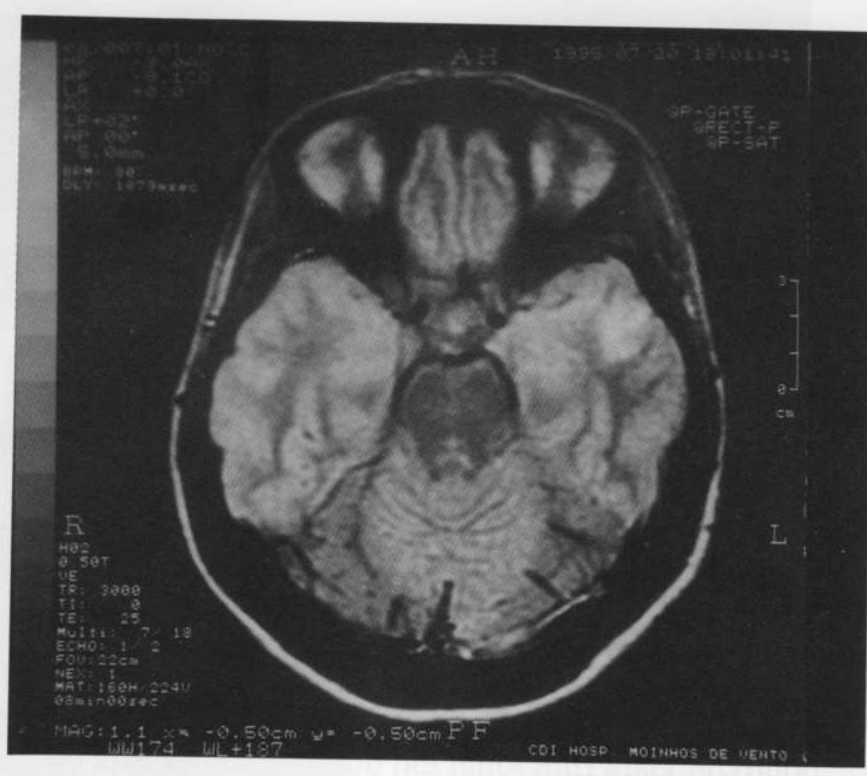

FIGURA 2

Exemplos de pequenas lesões epileptogênicas identificadas por estudos de imagem cerebral por ressonância magnética, nas quais a tomografia computadorizada de crânio foi interpretada como normal: A. Imagem coronal em T2 mostra atrofia e aumento de sinal intra-hipocampal à esquerda,

na imagem global e, melhor detalhado, na imagem focada das regiões têmporo-mesiais; B. Aumento focal da espessura cortical em giro frontal à direita, demonstrado por imagem axial em T2; C. Pequeno ganglioglioma localizado na porção anterior do lobo temporal esquerdo; D. Angioma cavernoso (cavernoma) temporalmesial direito. 


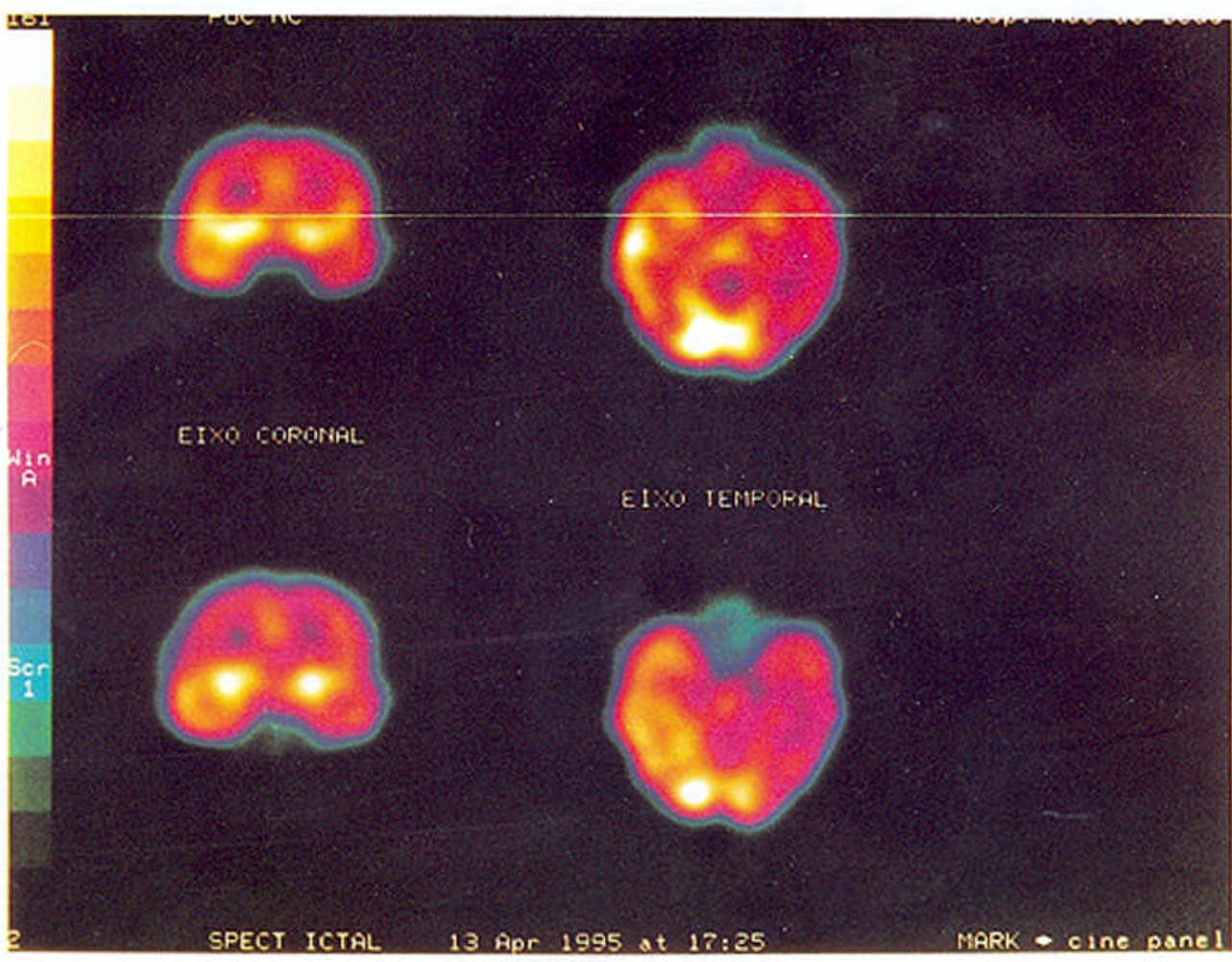

FIGURA 3

SPECT ictal nos planos coronal e axial, em paciente com crises originadas do lobo temporal esquerdo. Note nítido aumento da perfusão cortical ao longo de todo o lobo temporal esquerdo.

complementarem os achados estruturais, aportando dados independentes para o diagnóstico topográfico, muitas vezes estas técnicas vão ser as únicas a mostrarem anormalidades, no contexto de exames de neuroimagem estrutural normais. Técnicas de RM são aplicadas do ponto de vista funcional em duas situações específicas: espectroscopia por $\mathrm{RM}^{\mathrm{10}}$ e RM funcional per se. A espectroscopia por $\mathrm{RM}$ fornece dados a respeito da concentração intracelular de $\mathrm{N}$-acetyl aspartato (NAA), colina, creatina e fosfocreatina. Como o NAA localizase primariamente nos núcleos de neurônios, a redução das relaçôes entre NAA e colina, creatina e fosfocreatina é um marcador de perda ou disfunção neuronal ${ }^{10}$. Novamente, assimetrias entre regiōes temporais mesiais ou entre o córtex frontal de um e outro hemisfério permitem que se identifiquem alterações freqüentemente não-visíveis aos exames estruturais. Denomina-se RM funcional propriamente dita uma técnica ainda restrita à seara experimental, mas através da qual pode-se mensurar objetivamente o metabolismo de regiōes corticais através de técnicas de ressonância, obtendo-se informações semelhantes as obtidas através de tomografia por emissão de pósitrons $(\mathrm{PET})^{12}$, mas sem a necessidade da injeção de radiofármacos.

Na mesma direção, os estudos de perfusão cerebral e metabolismo cortical por tomografia computadorizada com emissẫo de fóton único (SPECT) e PET têm permitido a identificação de alteraçōes funcionais na região do cortex epileptogênico e à distância, que variam de acordo com o estado do paciente (periodo interictal, ictal ou pós-ictal) e auxiliam tanto no planejamento da estratégia operatória quanto na compreensão da extensão e da severidade das alteraçōes funcionais do córtex cerebral, o que parece ter impacto nos resultados cirúrgicos. Nos períodos interictal e pós-ictal, tanto PET quanto SPECT geralmente mostram redução seja da perfusão, seja do metabolismo na região cortical disfuncionada ${ }^{5} .12$.

Um aumento da atividade metabólica (raramente detectada por PET) e, especialmente, da perfusão cortical (frequientemente detectada por SPECT - figura 3) costuma ser observado focalmente durante uma crise epilética parcial ${ }^{5}$. Isso auxilia muito na localização da zona epileptogênica.

A realização de um procedimento cirúrgico motivado exclusivamente pela ocorrência de crises epiléticas refratárias ao tratamento farmacológico parte da premissa de que novos déficits não serão acrescentados, ou ao menos serão minimizados ao máximo e, neste segundo cenário, seu impacto funcional será consideravelmente menor do que aquele representado pelas crises recorrentes. Assim, uma série de medidas que fazem parte da avaliação pré-operatória são tomadas para minimizar os riscos de sequielas. Em termos de sequielas motoras e de linguagem, pacientes com perspectiva de ressecção em regiões próximas ao córtex motor primário ou regiões corticais possivelmente relacionadas a funções de linguagem são submetidos a um mapeamento funcional através de estimulação cortical $^{17}$. Este procedimento pode ser realizado a nível 
extra-operatório - quando lança-se mão da estimulação elétrica de contatos em placas de eletrodos subdurais implantadas sobre o córtex motor - ou durante a própria cirurgia ressectiva, através da estimulação do córtex motor sob visualização direta (figura 4).

Para salvaguardar as funções de memória, a avaliação pré-operatória conta com a participação de um neuropsicólogo. Uma testagem de funções de memória verbal e não-verbal é levada a cabo, o que fornece valiosa indicação a respeito do status funcional das estruturas temporais relacionadas a funções mnésticas em cada hemisfério. Além disso, a reserva funcional em relação às funções de memória (e aqui também de linguagem) são auferidas através do teste do Amytal sódico ${ }^{28}$. Resumidamente, este teste consiste na anestesia, por alguns minutos, das regiões de um hemisfério cerebral irrigadas por uma determinada artéria (geralmente a artéria carótida

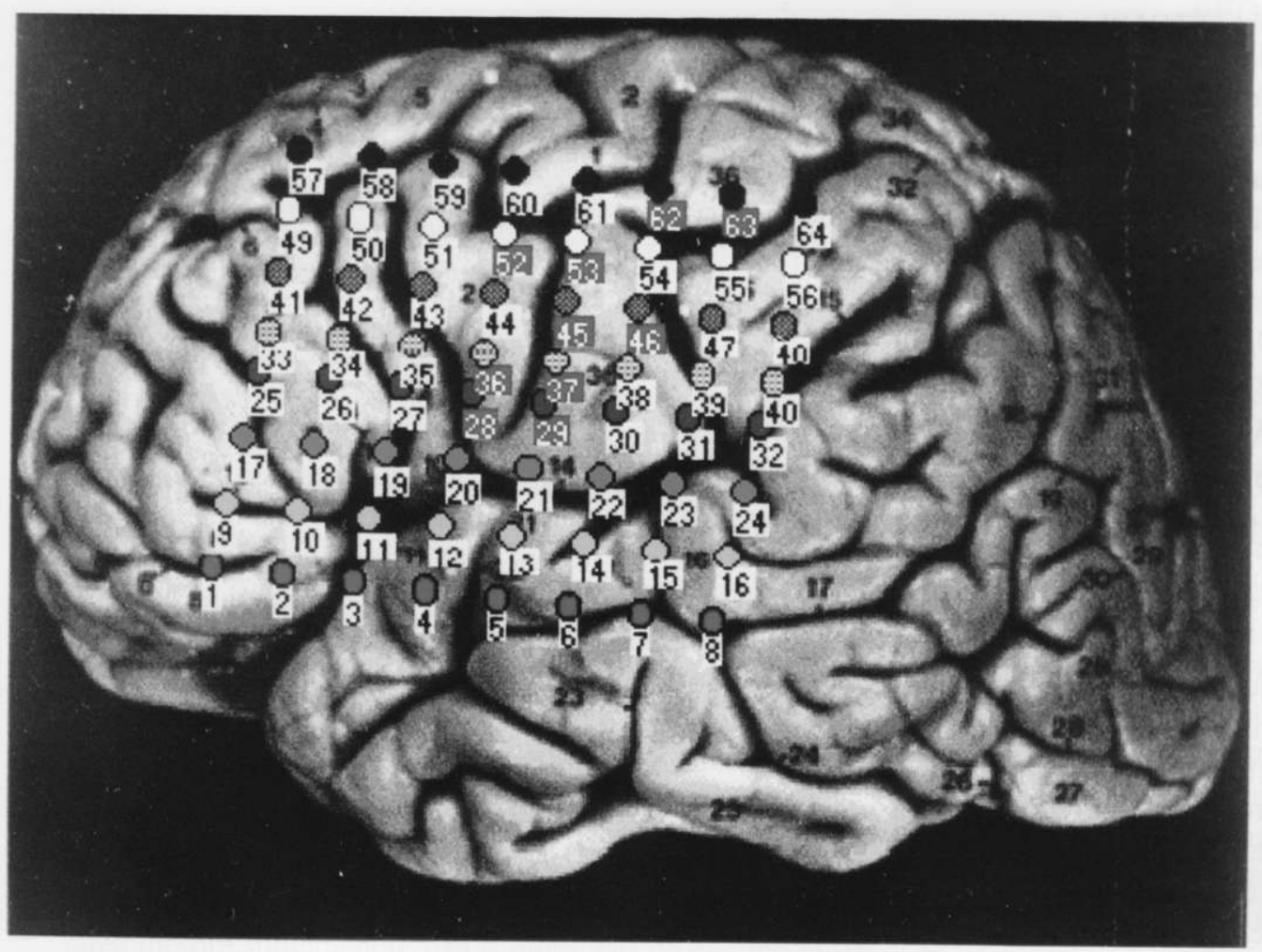

FIGURA 4

Representação esquemática de uma placa ('grid') 8x8, implantada no espaço subdural fronto-central esquerdo, para registro de crises e mapeamento funcional do córtex sensori-motor. Cada fileira horizontal de 8 contatos é representada por uma cor diferente. Contatos estão numerados de 1 a 64 . Numeração em vermelho indica os contatos (\#28, \#29, \#36, \#37, \#45, \#46, \#52, \#53, \#62, \#63) cuja estimulação elétrica produziu respostas motoras clônicas, sugerindo localização sobre o córtex motor primário. interna), através da injeção intra-arterial do Amytal sódico. Durante a anestesia, são testadas funções que, naturalmente, estarão sendo executadas por estruturas do hemisfério não-anestesiado. Isso permite a definição da existência de uma reserva funcional em termos de memória quando se antecipa uma ressecção temporal e também da dominância hemisférica para linguagem.

Outras funções cognitivas como as capacidades vísuo-espaciais, construcionais e as funções executivas são também testadas durante a bateria neuropsicológica, fornecendo indícios adicionais de disfunção em regiões corticais específicas.

Conforme mencionado na introdução deste artigo, com os avanços tecnológicos responde-se a algumas questões, mas geram-se outras. Por exemplo, estudos recentes com técnicas de PET a partir da injeção de ${ }^{11} \mathrm{C}$-Flumazenil para o estudo de receptores benzodiazepínicos têm sugerido que alguns tipos de lesões corticais aparentemente focais, bem localizadas, acompanham-se de alteração funcional bastante difusa, freqüentemente bilaterais $^{29}$. O significado em termos de planejamento terapêutico e definição prognóstica de achados deste tipo não está claro. Situações deste tipo exemplificam o quanto deve-se avançar no entendimento das múltiplas repercussões corticais de lesões epileptogênicas, certamente modificando conceitos mais simplistas de 'epilepsia parcial'. De qualquer forma, o primeiro passo para tais avanços depende da identificação e localização das anormalidades. O instrumental para tal foi apresentado acima. Com base neste conhecimento, passamos à etapa seguinte: a identificação e definição das diversas zonas ou áreas de alteração cortical no córtex do paciente epilético. 


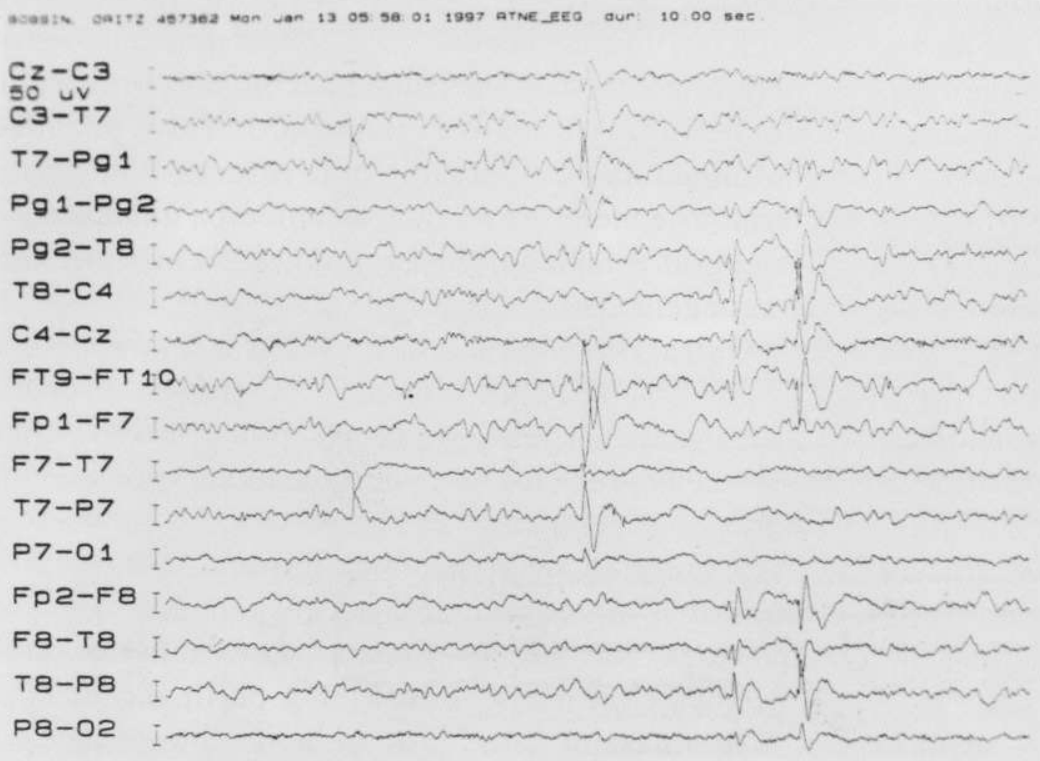

FIGURA 5

Registro do EEG interictal em paciente com epilepsia parcial e crises têmporolímbicas. Note descargas epileptogênicas registradas independentemente em ambos os lobos temporais. Numeração ímpar denota eletrodos à esquerda, par à direita. Pg1 e Pg2 identificam eletrodos zigomáticos.

é convergente com dados topográficos provindos de outras fontes, existe uma perspectiva de muito bom resultado cirúrgico. $\mathrm{Na}$ maioria das vezes, entretanto, a zona irritativa é multifocal, e apenas uma porção desta costuma fazer parte da zona epileptogênica. Exemplos comuns de multifocalidade das descargas interictais são as epilepsias frontais com descargas frontotemporais independentes, as epilepsias têmporo-límbicas com descargas independentes em ambos os lobos temporais (figura 5) e as displasias corticais localizadas, nas quais a distribuição das descargas interictais é via de regra bem mais extensa do que a lesão visível pela RM. Um aspecto interessante, e que demonstra o quanto a definição da extensão da zona irritativa é dependente da metodologia empregada para registro, é que quando se emprega eletrodos intracranianos para

CÓRTEX EPILEPTOGÊNICO: EXTENSÃO, HIERARQUIA, REPERCUSSÕES FUNCIONAIS, RELAÇÃO COM LESÕES ESTRUTURAIS E GRAUS DE CONVERGÊNCIA

Uma vez que um dos objetivos principais da avaliação pré-operatória de pacientes epiléticos, cujas crises são refratárias ao tratamento farmacológico é a localização de uma área cortical cuja ressecção levará ao controle das crises (zona epileptogênica), o instrumental discutido acima é todo mobilizado para tal finalidade. Os achados de cada teste, entretanto, aportam evidências localizatórias de natureza e relevância distintas. Talvez não seja exagero dizer que a "arte" contida em uma avaliação pré-operatória bem feita consiste de uma judiciosa integração de todos os achados localizatórios, sintetizados no delineamento o mais aproximado possível da 'zona epileptogênica'.

A distribuição (extensão) topográfica das descargas epileptogênicas interictais define o que se denomina zona irritativa. É muito raro que a zona irritativa seja estritamente unifocal; quando isso ocorre e a localização registro da atividade elétrica diretamente do córtex cerebral, descargas interictais são registradas sistematicamente em quase todas as regiões avaliadas, independentemente da área efetivamente responsável pelas crises ${ }^{22}$. Assim, a relevância exata da extensão das descargas interictais ainda hoje desafia os epileptologistas. Talvez a melhor definição das complexas relações entre zona irritativa e zona epileptogênica foi enunciada por Morrell ${ }^{16}$ : "Descargas epileptogênicas ao EEG são interpretadas como manifestação de atividade sináptica hipersíncrona de neurônios corticais. Estas descargas são vistas como representando um processo epileptogênico em potencial, e assim o registro destes eventos elétricos paroxísticos ao EEG estabelece a possibilidade de que crises epiléticas possam originar-se de células que exibem tal atividade elétrica anormal, seja no presente, seja no futuro."

A seguir, deve-se localizar a região de origem das crises habituais do paciente. Esta "zona de origem das crises" é determinada idealmente através da correlação entre a localização e a evolução das alterações eletrencefalográficas ictais e a semiologia e a evolução temporal da crise, conforme visualizados pelo registro simultâneo videoeletrencefalográfico. Esta correlação é muito 


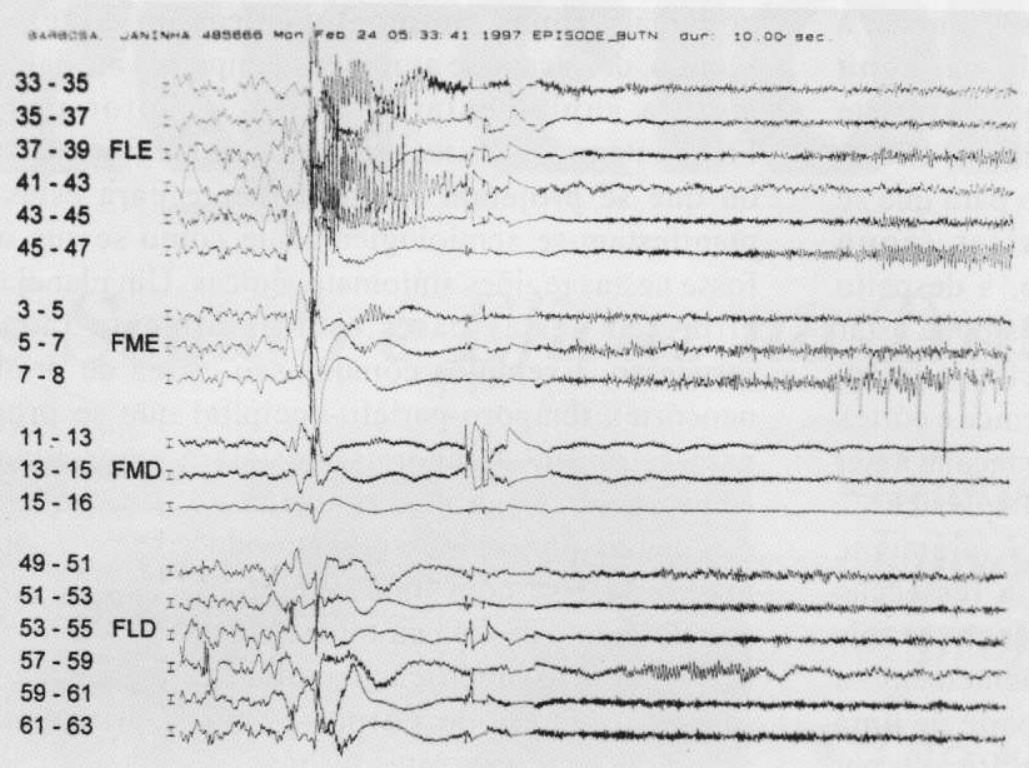

A

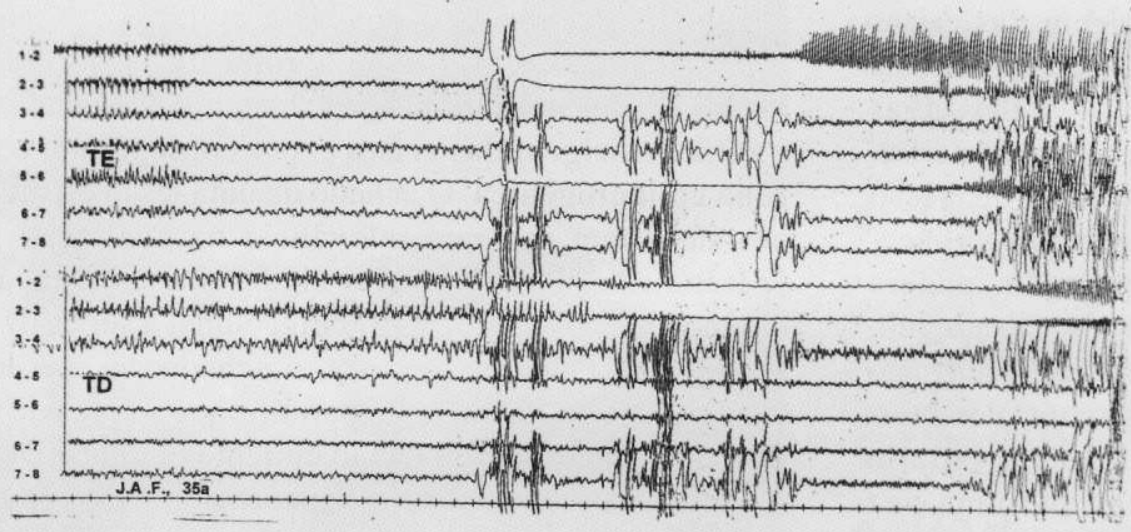

B

\section{FIGURA 6}

A. Registro ictal obtido através de eletrodos intracranianos ('subdural strips') implantados nas regiões frontais lateral e mesial de ambos os hemisférios, em paciente com crises tônicas sugestivas de origem ou acometimento precoce de área motora suplementar. EEGs interictais de escalpo mostravam descargas bifrontais ora independentes, ora síncronas, e os registros ictais não permitiam localização intra ou inter-hemisférica. Note nítida lateralização do início das crises em estruturas do lobo frontal esquerdo; B. Registro ictal intracraniano em

paciente com crises têmporo-límbicas no qual 'strips' subdurais foram implantados na superfície ínfero-mesial de ambos os lobos temporais. EEGs interictais de escalpo mostravam descargas bitemporais independentes e EEG ictal de escalpo não evidenciou lateralização satisfatória. Crises foram registradas com origem exclusivamente no lobo temporal esquerdo (note intensa atenuação

da atividade elétrica no início da crise em TE 1-2 [contatos mais mesiais]). importante, pois muitas vezes o EEG mostra uma atividade ictal enquanto o paciente não apresenta uma crise clinicamente definida ou, por outra, uma crise observada no vídeo pode iniciar-se vários segundos antes que se identifique as primeiras alterações ictais ao EEG. Este último cenário costuma sugerir que a crise inicia-se de uma região cortical que não está sendo adequadamente registrada pelos eletrodos de superfície.

Em diversas ocasiões, principalmente nas epilepsias extratemporais e em alguns pacientes com epilepsias temporais mas descargas interictais bilaterais independentes, os registros ictais obtidos através de EEGs de superfície são altamente insatisfatórios para a localização da zona de origem das crises. Isso se deve seja à rápida propagação da atividade ictal para outras áreas, seja a sua origem em estruturas corticais não-avaliadas apropriadamente com eletrodos de superfície (como é o caso das regiões frontais orbitais e mesiais, do córtex parieto-occipital mesial e da porção inferior dos lobos temporais). Assim, lança-se mão de eletrodos intracranianos, com o intuito de registrar-se diretamente dos geradores das crises $^{22}$ (figura 6: a, b). O problema é decidir quais regiões corticais dentro da zona irritativa definida ao EEG de escalpo (ou até mesmo fora dela) que devem ser avaliadas por estes eletrodos intracranianos. Uma parte desta questão é respondida quando uma lesão estrutural (lesão epileptogênica) é identificada pela RM. Entretanto, na ausência de uma lesão visível, a estratégia de investigação com eletrodos intracranianos para localizar a zona de origem das crises depende de uma judiciosa análise dos dados clínicos, semiológicos, e daqueles dados (mesmo que incompletos) obtidos através da investigação inicial com EEGs de escalpo. 
O conceito de zona de origem das crises parece, à primeira vista, misturar-se com aquele de zona epileptogênica. Entretanto, especialmente quando existe uma lesão estrutural associada, identificada por RM, a quantidade de tecido que deve ser excisado para que se obtenha um controle completo das crises (zona epileptogênica) geralmente inclui a lesão, a despeito do fato de que a zona de origem das crises pode estar localizada no córtex perilesional e não incluir a lesão. As efetivas interações entre lesão epileptogênica e córtex epileptogênico somente recentemente começam a ser elucidadas, em especial para as lesões displásicas ${ }^{20}$. Entretanto, parece bem estabelecido que raramente obtêm-se resultados satisfatórios quando a ressecção cirúrgica não inclui a lesão estrutural, qualquer que seja sua natureza ${ }^{23}$. Deve ficar claro que freqüentemente a zona de origem das crises é apenas uma parte de uma zona irritativa mais extensa, como exemplificado por pacientes com descargas epileptogênicas interictais bitemporais independentes, mas cujas crises iniciam-se consistentemente de apenas um dos lobos temporais ${ }^{33}$. A mensagem aqui é que a zona de origem das crises funciona como a região marca-passo, ou seja, aquela região cortical onde ocorrem as primeiras descargas ictais. Em outras palavras, é o ponto de partida da crise, podendo, a partir desta área, ocorrer ou não propagação da atividade ictal para outras regiões corticais conectadas sinapticamente. Havendo propagação, poderá haver acréscimo de sintomas, conforme descrito a seguir.

Relacionada à zona de origem das crises, mas não necessariamente sobreposta espacialmente, devemos definir uma zona sintomatogênica. Como o próprio nome diz, trata-se da região cortical que uma vez invadida pela atividade epileptogênica ictal determina o aparecimento de sintomas e sinais que expressam a semiologia da crise, e são identificáveis pelo paciente (auras) ou por outros observadores. Dominar o conceito de zona sintomatogênica é fundamental para que não haja precipitação quanto à definição da zona de origem das crises. Em outras palavras, existe uma tendência natural a atribuir-se a origem das crises à região cortical que costuma expressar-se ictalmente pelos sinais e sintomas apresentados pelo paciente durante a crise. Isso é bastante lógico, mas não necessariamente correto. Crises que se originam em regiões corticais com pouca ou nenhuma expressão clínica ictal podem apresentar sinais e sintomas somente após propagarem-se para regiões mais comumente sintomatogênicas. Assim, localizar-se a origem das crises à zona sintomatogênica pode ser um erro, pois esta última talvez represente apenas a região para a qual a crise - originada alhures propagou-se. É importante que se conheça algumas das principais zonas sintomatogênicas do córtex. Neste sentido, destacam-se as regiões temporais mesiais, a área motora suplementar e o córtex motor primário. Frequientemente, crises originadas em regiões adjacentes ou que se projetam sinapticamente para estas áreas manifestam-se semiologicamente como se sua origem fosse nestas regiões sintomatogênicas. Um planejamento cirúrgico nestas bases está geralmente fadado ao insucesso. Exemplos comuns são crises de origem no neocórtex têmporo-parieto-occipital que se propagam para estruturas temporais mesiais e apresentam uma semiologia típica destas últimas ${ }^{27}$, ou ainda crises originadas em regiões diversas do córtex frontal que manifestam-se com uma semiologia característica de envolvimento de área motora suplementar - início súbito de posturas assimétricas envolvendo extremidades em ambos os lados do corpo - após a propagação da atividade ictal para estas últimas.

Conforme mencionado anteriormente, avanços tecnológicos recentes nas técnicas de imagem têm permitido a identificação cada vez maior de lesões estruturais discretas associadas à epilepsia. A região cortical que contém a lesão, 'zona de lesão epileptogênica', costuma estar espacialmente relacionada com a zona de origem das crises e, por conseguinte, com a zona epileptogênica. $\mathrm{O}$ achado de uma lesão estrutural, portanto, tem extrema relevância na avaliação préoperatória, podendo abreviar alguns passos e impactar diretamente na estratégia investigacional a ser utilizada. Em epilepsias extratemporais, o achado de uma lesão estrutural pode, de um lado, permitir que se planeje uma ressecção da lesão e do tecido epileptogênico adjacente identificado por registros eletrocorticográficos agudos, transoperatórios, ou de outro, indicar onde devem ser colocados eletrodos intracranianos ${ }^{22}$. Qualquer um destes dois cenários é muito mais confortável do que a situação descrita acima na qual eletrodos intracranianos devem ser implantados no neocórtex na tentativa de registrar-se a zona de origem das crises, sem que haja uma lesão estrutural associada (portanto, apenas em bases semiológicas e eletrográficas interictais ${ }^{22}$.

Uma ressecção o mais completa possível da lesão estrutural costuma ser um pré-requisito para que crises epiléticas a ela relacionadas sejam completamente controladas. Isso está bem determinado para lesões de diversos tipos, incluindo displasias corticais, lesões glióticas pós-traumáticas, cavernomas, tumores de crescimento lento, e naturalmente, esclerose hipocampal $^{3,20,23}$. Uma questão que freqüentemente se coloca é o quanto de tecido cortical adjacente (ou não) à lesão deve ser incluído na ressecção para que haja um controle satisfatório das crises. Isso parece variar com 
a natureza da lesão, mas via de regra o córtex epileptogênico peri-lesional - identificado pelos estudos eletrencefalográficos pré-operatórios e/ou através de eletrocorticografia transoperatória - deve ser incluído na ressecção, desde que isso seja funcionalmente seguro. Este certamente é o caso no que diz respeito a lesões displásicas localizadas, onde a margem da ressecção deve ser determinada pela distribuição das descargas epileptogênicas ao eletrocorticograma, especialmente quando descargas contínuas ou semicontínuas estão presentes $^{24}$.

O conceito de zona de déficit funcional cortical é aquele que mais tem se expandido, em função do emprego crescente de técnicas de SPECT, PET e espectroscopia por RM. Déficit funcional cortical é um conceito abrangente, que envolve desde a inferência de uma alteração no córtex motor de um paciente epilético com hemiparesia. Mais comumente, valoriza-se a distribuição espacial de atividade lenta (delta) ao EEG ou ao eletrocorticograma e os achados de alteração cognitiva aos testes neuropsicológicos (conforme acima). O que deve ficar claro desde o princípio é que alteração de neurônios corticais ou de suas conexões funcionalmente relevantes manifesta-se não apenas por atividades epileptogênicas - interictais e/ou ictais - mas também por indicativos de disfunção cortical, como atividade lenta focal, déficit de funções cognitivas relacionadas à área cortical em questão, bem como redução focal na perfusão e no metabolismo neuronal. Estes últimos são detectados por SPECT e PET ou espectroscopia por RM, respectivamente, no período interictal. O que tem sido visto cada vez mais é que a extensão da zona de déficit funcional cortical é frequientemente bem maior do que se imaginaria à primeira vista ${ }^{29}$. Técnicas eletrográficas, neuropsicológicas ou de neuroimagem costumam mostrar alterações em áreas corticais adjacentes e/ou à distância de zonas de origem de crises ou de zonas de lesão estrutural claramente visíveis à RM. O significado exato destas alterações corticais funcionais à distância não está claro. Em outras palavras, não se sabe até que ponto representam apenas disfunções induzidas por via sináptica em áreas corticais estruturalmente normais, ou se alterações estruturais microscópicas estão presentes, sejam primárias ou secundárias ao "bombardeamento epilético, 16, 32. Além disso, o impacto da presença, extensão e natureza destas áreas de disfunção cortical à distância na determinação da estratégia cirúrgica e nos resultados do tratamento cirúrgico ainda não está definido, mas provavelmente será uma das questões mais importantes dos próximos anos na área da cirurgia da epilepsia.

\section{Os novos desafios para a localização da zona epileptogênica}

O acréscimo crescente de novas e potentes técnicas de investigação de alterações corticais, sejam eletrográficas, estruturais ou funcionais, tem tornado cada vez mais complexa a determinação da localização da zona epileptogênica. Ou seja, está cada vez mais difícil encontrar-se pacientes nos quais todos os dados localizatórios apontam para uma restrita e bem localizada região cortical. Convergência espacial total dos dados localizatórios é quase um conceito abstrato! Interessantemente, há pouco mais de uma década atrás o grau de convergência era 'aparentemente mais perfeito': bastava que a semiologia das crises e os dados do EEG concordassem espacialmente para que se pudesse imaginar estar definida a contento a extensão da zona epileptogênica. Hoje em dia, é fundamental que se adicione o conceito de hierarquia das informações localizatórias. Como é muito improvável que todas as zonas de disfunção estejam co-localizadas espacialmente, é necessário que se estipule quais informações têm maior relevância para a melhor localização possível da zona epileptogênica. Este conceito de hierarquia, muito embora intuitivamente correto, ainda está em seus primórdios, e certamente corresponderá a um dos mais importantes avanços conceituais dos próximos anos. Estudos correlativos, de preferência prospectivos, analisando os resultados cirúrgicos de acordo com quais parâmetros foram considerados mais relevantes na definição da extensão de tecido cortical a ser ressecado (potencial zona epileptogênica), serão necessários para a consumação destes avanços ${ }^{34}$.

Apenas para exemplificar este cenário, considere-se um paciente com crises parciais complexas sugestivas de origem têmporo-límbica, de etiologia pós-encefalítica, no qual os registros videoeletrencefalográficos mostram descargas bitemporais independentes com predomínio à esquerda, crises eletroclínicas registradas no lobo temporal esquerdo, RM com esclerose hipocampal à esquerda, mas SPECT interictal e dados da avaliação neuropsicológica apontando para disfunção no lobo temporal direito. Neste exemplo real, teve que ser levado em conta para a definição da zona epileptogênica o peso localizatório, hierarquicamente falando, das alterações estruturais e da zona de origem de crises localizadas no lobo temporal esquerdo versus o peso localizatório das alterações funcionais (zona de déficit funcional cortical) no lobo temporal direito. Cenários muito mais complexos começam a ser identificados, quando, por exemplo, acrescentam-se dados de PET scan e espectroscopia por RM, além de todas as outras 
técnicas, a pacientes com epilepsias extratemporais. Existe um vasto campo de pesquisa à frente, com a perspectiva de propiciar um melhor conhecimento da neurobiologia dos diversos tipos de epilepsias parciais e, por conseguinte, melhores resultados cirúrgicos.

\section{DIAGNÓSTICO TRI-AXIAL EM EPILEPTOLOGIA: O ENCONTRO DA TOPOGRAFIA COM A HISTÓRIA NATURAL, DEFININDO AS ESTRATÉGIAS DE AVALIAÇÃO E CIRURGIA}

Durante muito tempo, a inegável necessidade de um diagnóstico topográfico preciso como pré-requisito sine qua non para a ressecção do tecido cortical responsável pelas crises eclipsou a relevância dos diagnósticos etiológico e sindrômico ${ }^{25}$ no processo de avaliação précirúrgica em epileptologia. Até porque o instrumental apropriado para melhores definições etiológicas (e sindrômicas) tem se tornado disponível apenas em anos recentes, o papel da etiologia da lesão cortical responsável pela epilepsia era tradicionalmente secundário. Este cenário mudou drasticamente. Hoje sabe-se que tanto a avaliação pré-cirúrgica quanto a própria estratégia operatória devem ser individualizadas ('tailored') para tipos específicos de lesões e de síndromes (subsíndromes) epiléticas ${ }^{23,25}$.

Isso tem vários desdobramentos, dos quais 4 são fundamentais. A identificação de uma etiologia/ síndrome específica fornece informações muito relevantes sobre (i) a história natural predizível da evolução da epilepsia, (ii) a extensão de tecido cortical que costuma estar envolvido no processo epileptogênico e a forma de localizá-lo apropriadamente, e (iii) a estratégia cirúrgica que costuma acompanhar-se dos melhores resultados, tanto em relação ao controle das crises quanto em termos funcionais, e (iv) o prognóstico do tratamento cirúrgico.

Assim, pacientes com epilepsia têmporo-límbica e história de convulsões febris prolongadas na infância freqüentemente apresentam, como substrato patológico, uma esclerose hipocampal ${ }^{30}$ (freqüentemente confirmada por $\mathrm{RM}^{4}$ ); por sua vez, a síndrome de epilepsia têmporo-límbica associada à esclerose hipocampal costuma ser de difícil controle medicamentoso, associar-se a alterações patológicas seja exclusivamente unilaterais ou bilaterais assimétricas, apresentar descargas epileptogênicas interictais uni- ou bitemporais, ter crises eletrográficas registradas com um padrão específico de descargas ictais, e assim por diante $^{36}$. Ainda dentro deste exemplo, sabe-se que esta síndrome específica costuma ter crises originadas exclusivamente em um dos lobos temporais, a despeito dos pacientes freqüentemente apresentarem descargas interictais bitemporais independentes ${ }^{33}$. Identificada (ou suspeitada) a síndrome, deve-se esperar um conjunto de achados relativamente previsíveis, podendo-se, assim, antecipar um prognóstico altamente favorável ${ }^{36}$. Incongruências a qualquer nível devem levantar uma forte suposição de que o paciente apresenta uma forma diferente de epilepsia, quando então terá de ser investigado de forma distinta e terá um prognóstico cirúrgico diferente.

Um exemplo adicional para ilustrar estes conceitos seria a avaliação de um paciente com uma lesão cortical displásica. De acordo com as características por RM pode-se identificar o tipo macroscópico de displasia, o que permite inferências quanto às alterações histopatológicas. De acordo com os tipos de alterações histopatológicas da lesão displásica, variam a severidade da epilepsia, a severidade das alterações eletrográficas e a provável extensão de tecido cortical envolvido pela patologia $^{26}$. Isso, por sua vez, determinará a necessidade ou não de utilizar-se eletrodos intracranianos (placas subdurais) ou registros eletrocorticográficos transoperatórios para mapear a zona de origem das crises ou a presença e extensão de descargas epileptogênicas contínuas, cuja ressecção é crucial para que um bom prognóstico seja alcançado. Isso muda, por exemplo, a abordagem diagnóstica e cirúrgica de um paciente com displasia cortical focal tipo Taylor, associada à presença de neurônios displásicos e células em balão, daquela de um paciente com uma esquizencefalia localizada, cuja histopatologia é inteiramente diferente ${ }^{26}$. Da mesma forma, alguns tipos de lesões displásicas, como as heterotopias periventriculares costumam estar associadas à presença de esclerose hipocampal ou, ao menos, de crises de origem aparentemente têmporolímbicas. Estudos recentes, entretanto, têm mostrado que os resultados de lobectomia temporal nestes pacientes são muito pouco satisfatórios, o que vai desafiar os epileptologistas a elaborarem estratégias cirúrgicas distintas, para que se venha a obter melhores resultados ${ }^{9}$.

Mais ainda do que nas situações exemplificadas acima, talvez o conjunto de situações em que os diagnósticos topográfico, etiológico e sindrômico mais interajam para definir estratégias de avaliação e cirurgia seja nas epilepsias catastróficas da infância. Este conceito engloba síndromes epiléticas que caracterizamse por crises que iniciam-se nos primeiros dias, meses, ou anos de vida, as quais são extremamente freqüentes, 
refratárias ao tratamento farmacológico e, principalmente, associam-se a déficits motores e cognitivos progressivos. Espasmos infantis, hemimegalencefalias e encefalite crônica de Rasmussen são exemplos de síndromes epilépticas catastróficas da infância $^{2,31,35}$. A definição etiológica e sindrômica, no contexto de crises refratárias, deve levar a uma avaliação pré-operatória que identifique, principalmente, zonas de disfunção cortical, incluindo déficits motores préexistentes. Como os procedimentos cirúrgicos indicados para estas síndromes são extensas ressecções hemisféricas, freqüentemente chegando à hemisferectomia, é fundamental que a avaliação pré-operatória, já antevendo tal estratégia, defina as reservas funcionais e as perspectivas de reabilitação em termos motores e cognitivos. Isso se obtém, por exemplo, através da avaliação funcional do hemisfério não-patológico com EEG, PET, SPECT ou espectroscopia por RM. Nestas situações isso é mais importante do que preocupar-se em detalhar a porção exata de tecido cortical que está originando as crises em um dado momento. Este tipo de decisão durante a investigação pré-operatória decorre diretamente de diagnósticos sindrômicos e etiológicos corretos.

\section{Relevância dos diagnósticos etiológico e sindrômico na modificação conceitual dos objetivos cirúrgicos nas epilepsias catastróficas da infância}

A definição etiológica e sindrômica através de dados clínicos e de neuroimagem permite a previsão com suficiente segurança da história natural das crises e das alterações motoras e cognitivas em crianças com epilepsias catastróficas. Isso tem levado à ampliação dos objetivos cirúrgicos nestes pacientes. Ao invés de conceber-se o ato cirúrgico apenas com o intuito de controlar as crises refratárias, avança-se conceitualmente para incluir também o objetivo de estimular o desenvolvimento motor e cognitivo. Isso, naturalmente, baseia-se em conhecimentos a respeito dos aspectos temporais da plasticidade cerebral para funções motoras, visuais e de linguagem. Sendo mais explícito: pacientes com deterioro progressivo ou falha no desenvolvimento de funções cognitivas, no contexto de lesões hemisféricas extensas (figura 7), freqüentemente melhoram com a ressecção do hemisfério afetado, o qual geralmente interfere com o desenvolvimento e a transferência de funções cognitivas para o 'hemisfério bom, $2,31,35$. Esta transferência é grandemente estimulada pelo procedimento cirúrgico, levando

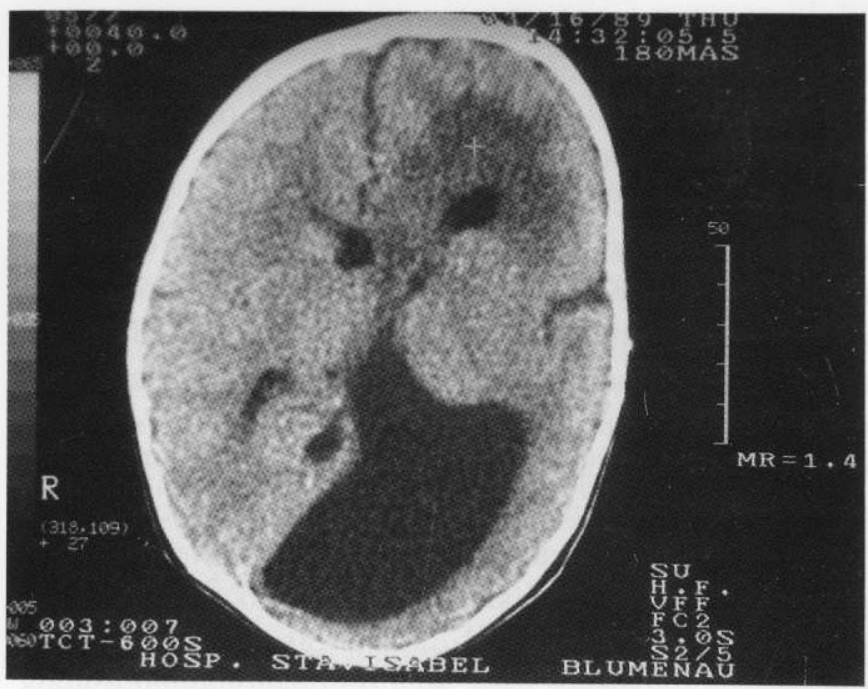

\section{FIGURA 7}

Tomografia computadorizada de crânio em paciente de 7 anos de idade com frequientes crises parciais motoras com generalização secundária, refratárias aos fármacos antiepiléticos e associadas a progressivo deterioro cognitivo. Note nítida assimetria entre os hemisférios cerebrais com um aumento de volume à esquerda caracterizando hemimegalencefalia.

a significativas melhoras funcionais, além do controle das crises. Este estímulo ao desenvolvimento e transferência de funções nobres através de uma cirurgia ressectiva extensa quase que constitui-se num fim em si (Até quando o quase persistirá em sentenças como esta é uma pergunta legítima).

\section{EPILEPSIAS FOCAIS: REVISÃO CONCEITUAL E IMPLICAÇÕES PRÁTICAS}

Em sintonia com a tônica deste artigo, não há como encerrar sem sintetizar os desdobramentos que decorrem do principal subproduto de todos os avanços tecnológicos com que temos sido contemplados para realizar a avaliação pré-operatória em pacientes epiléticos: o desafio ao conceito de epilepsia focal.

A idéia de que subjacente a um 'foco epilético' sempre havia uma lesão estrutural é antiga e tem sido ensinada para gerações e gerações de neurologistas ao longo deste século. Entretanto, como até muito recentemente não se tinha como identificar nem esta 'tal lesão' e nem os efeitos por ela provocados sobre o 
funcionamento do córtex cerebral, floresceu o conceito de que 'um foco é um foco', ou seja, uma área relativamente restrita, bem localizada, onde concentravam-se todas as anormalidades e de onde originavam-se as crises. O conceito de 'foco epilético' mudou. Conforme discutido acima, aquele 'foco' que aprendemos a não mais de uma década atrás é um conceito abstrato, com múltiplas facetas, via de regra não-restrito a uma única, limitada, área cortical. Hoje em dia, em cada paciente, identifica-se o 'foco' de descargas interictais (zona irritativa), o 'foco' de onde se originam as crises (zona de início das crises), o 'foco' de lesão estrutural, o 'foco' de alterações da perfusão, do metabolismo e da função cortical, etc. Estes avanços não invalidam o fato de que, eventualmente, define-se uma área hierarquicamente mais relevante nos pacientes com epilepsias 'focais'. Mas no momento em que nos obrigamos a incluir a noção de hierarquia de alterações, fica claro que estamos mudando o conceito de 'foco epilético'. Naturalmente, a avaliação pré-cirúrgica deve acompanhar estas mudanças.

A noção de continuum de severidade ou de extensão topográfica do 'foco' é um dos conceitos que deverão emplacar nos próximos anos. Para cada patologia (substrato etiológico, estrutural) que define uma síndrome ou subsíndrome epilética, é muito provável que os pacientes distribuam-se ao longo de um espectro de alterações. Alguns serão 'focais focais', ocupando um extremo do continuum. Neles, a convergência de todas as alterações semiológicas, eletrográficas, neuropsicológicas, estruturais, metabólicas e perfusionais tenderão, sim, a co-localizarem-se em uma região cortical restrita. À medida em que avançamos em direção ao outro extremo deste continuum, encontraremos pacientes com graus progressivamente maiores de 'conflitos de localização', ou seja, com extensões maiores ou topograficamente divergentes dos diversos níveis de alteração cortical, a despeito da patologia ser a mesma e, muitas vezes, da extensão da lesão visível à RM ser a mesma de pacientes com focos bem restritos. Situações deste tipo talvez estejam na raiz das causas de porquê, por exemplo, apenas metade dos pacientes com uma entidade aparentemente homogênea - epilepsia têmporo-límbica associada à esclerose hipocampal confirmada histologicamente - permanecem livres de crise após 5 anos de acompanhamento pós-operatório ${ }^{6,34}$. A resolução dos 'conflitos de hierarquia topográfica' com uma maior base neurobiológica, gerando melhores resultados cirúrgicos, é o grande desafio à frente dos profissionais envolvidos na avaliação pré-cirúrgica de pacientes epiléticos.

\section{SUMMARY}

The remarkable technological advances which have been introduced in the recent years allowed a progress in the presurgical evaluation in patients with refractory epilepsy. In order to spatially delineate the epileptogenic zone (i.e. the cortical region whose resection is both necessary and sufficient to achieve seizure control), it is imperative to have a clear understanding of the localizing value pertaining to each method of evaluation. Since localizing data obtained through modern imaging and neurophysiological techniques are not always entirely convergent, it is also necessary to advance conceptually, pari pasu with the technological innovations. This paper reviews the techniques and concepts applied in the delineation of the epileptogenic zone and discusses the need for a triaxial (topographic, etiological and syndromic) diagnosis of the epileptic disorder. Finally, it adresses some discussion on new concepts regarding focal epilepsies.

\section{KEY WORDS}

Presurgical evaluation, refractory epilepsy, surgical results.

\section{Referências}

1. Agostini, M.; Passaro, E.; Engel, J. Jr; Vickrey, B.; Rausch, R. Dynamic outcome patterns 10 years following anterior temporal resection for intractable seizures (abstr). Epilepsia 37 (supp): 210, 1996.

2. Andermann, F.; Freeman, J.M.; Vigevano, F.; Hwang, P.A.L.S Surgically remediable diffuse hemispheric syndromes. In: Engel, J. Jr ed. Surgical Treatment of the Epilepsies, Second Edition. New York, Raven Press, 87-101, 1993.

3. Arruda, F.; Cendes, F.; Andermann, F.; Dubeau, F.; Villemure, J.G.; Jones-Gotman, M.; Poulin, N.; Arnold, D.; Olivier, A Mesial atrophy and outcome after amygdalohippocampectomy or temporal lobe removal. Ann. Neurol., 40: 446-450, 1996.

4. Berkovic, S.; Andermann, F.; Olivier, A. Hippocampal sclerosis in temporal lobe epilepsy demonstrated by magnetic resonance imaging. Ann. Neurol., 29: 175-182, 1991.

5. Berkovic, S.F.; Newton, M.R.; Rowe, C.C. Localization of epileptic foci using SPECT. In: Lüders. H.O. (ed). Epilepsy Surgery. New York, Raven Press, 251-256, 1992.

6. Berkovic, S.F.; Mclntosh, A.M.; Kalnins, R.M. Preoperative MRI predicts outcome of temporal lobectomy: an actuarial analysis. Neurology, 45: 1358-1363, 1995.

7. Cendes, F.; Andermann, F.; Gloor, P. MRI volumetric measurements of amygdala and hippocampus in temporal lobe epilepsy. Neurology, 43: 719-725, 1993.

8. Cendes. F.; Cook, M.J.; Watson, C.; Andermann, F.; Fish, D.R.; Shorvon, S.D. Frequency and characteristics of dual pathology in patients with lesional epilepsy. Neurology, 45: 2058-2064, 1995.

9. Dubeau, F.; Tampieri, D.; Lee, N.; Andermann, E.; Carpenter, S.; Leblanc, R.; Olivier, A.; Radtke, R.; Villemure, J.G.; Andermann, F. Periventricular and subcortical nodular heterotopia: a study of 33 patients. Brain, 118: $1273-1287$, 1995.

10. Duncan, J.S. Magnetic resonance spectroscopy. Epilepsia, 37: 598-605, 1996

11. Engel, J. Jr; Van Ness, P.C.; Rasmussen, T.B.; Ojemann, L. Outcome with respect to epileptic seizures. In: Engel, J. Jr ed. Surgical Treatment of the Epilepsies. Second Edition, New York, Raven Press, 609 -621, 1993.

12. Henry, T.H. Functional neuroimaging with positron emission tomography. Epilepsia, 37: 1141-1154, 1996.

13. Jack, C.R. Jr. Magnetic resonance imaging in epilepsy. Mayo Clin. Proc., 71: 695-711, 1996.

14. Jackson, G.D.; Connelly, A.; Duncan, J.S.; Grunewald, R.A.; Gadian, D.G. Detection of hippocampal pathology in intractable partial epilepsy: increased sensitivity with quantitative magnetic resonance T2 relaxometry. Neurology, 43: 1793-1799, 1993. 
15. Lüders, H.O.; Awad, I. Conceptual considerations. In: Lüders, H.O. ed. Epilepsy Surgery. New York, Raven Press, 51-62, 1992.

16. Morrell, F. Varieties of human secondary epileptogenesis. J. Clin. Neurophysiol., 6: 227-275, 1989.

17. Ojemann, G.A.; Sutherling, W.W.; Lesser, R.P.; Dinner, D.S.; Jayakar, P.; Saint-Hilaire, J.M. Cortical stimulation. In: Engel, J. Jr ed. Surgical Treatment of the Epilepsies. Second Edition, New York, Raven Press, 399-414, 1993.

18. Palmini, A. Padrōes eletroclínicos e neurorradiológicos nas epilepsias de lobo temporal e frontal refratárias ao tratamento medicamentoso: critérios de seleção e prognóstico do tratamento cirúrgico. Jornal da Liga Brasileira de Epilepsia, 4: 23-35, 1991.

19. Palmini, A.; Andermann, F.; Olivier, A. Focal neuronal migration disorders and intractable partial epilepsy: a study of 30 patients. Ann. Neurol., 30: 741-749, 1991.

20. Palmini, A.; Andermann, F.; Olivier, A.; Tampieri, D.; Robitaille, $Y$. Focal neuronal migration disorders and intractable partial epilepsy: Results of surgical treatment. Ann. Neurol., 30: 750 757, 1991.

21. Palmini, A.; Gloor, P. The localizing value of auras in partial epilepsy: A prospective and retrospective study. Neurology, 42: 801-808, 1992.

22. Palmini, A.; da Costa, J.C.; Kim, H.I.; Choi, H.Y. Indications for and types of intracranial electrode studies in patients with intractable epilepsy. Jornal da Liga Brasileira de Epilepsia, 6: 119-126, 1993.

23. Palmini, A.; Gambardella, A.; Andermann, F. Operative strategies for patients with cortical dysplastic lesions and intractable epilepsy. Epilepsia, 35 (Suppl 6): S57-S71, 1994.

24. Palmini, A.; Gambardella, A.; Andermann, F. et al. Intrinsic epileptogenicity of human dysplastic cortex as suggested by corticography and surgical results. Ann. Neurol., 37:476-487, 1995.

25. Palmini, A.; Calcagnotto, M.E. Epilepsias refratárias: Diagnóstico sindrômico, topográfico e etiológico. In: Guerreiro, C.A.M.; Guerreiro, M.M. eds. Epilepsia. Segunda Edição, São Paulo, Lemos, 391-411, 1996.

26. Palmini, A.L.F. Displasias Corticais Associadas à Epilepsia: delineamento de uma nova síndrome, revisão de conceitos localizacionais e proposta de uma nova classificação. Campinas: 1996, 182 p. Tese (Doutorado)-Unicamp.

27. Palmini, A.; Andermann, F.; Dubeau, F.; da Costa, J.C.; Calcagnotto, M.E.; Gloor, P.; Olivier, A.; Paglioli, E.; Paglioli-Neto, E. Occipito-temporal relationships: evidence for secondary epileptogenesis. In: Stefan, H.; Andermann, F.; Shorvon, S.D.; Chauvel, P. eds. Plasticity and Epilepsy, Advances in Neurology. New York, Lippincott-Raven, 1997, (in press).
28. Rausch, R.; Babb, T.L.; Engel, J.Jr.; Crandall, P.H. Memory following intracarotid amobarbital injection contralateral to hippocampal damage. Arch. Neurol., 46; 783-788, 1989.

29. Richardson, M.P.; Koepp, M.J.; Brooks, D.J.; Fish, D.R.; Duncan, J.S. Benzodiazepine receptors in focal epilepsy with cortical dysgenesis: an ${ }^{11} \mathrm{C}$-Flumazenil PET study. Ann. Neurol., 40: 188-198, 1996.

30. Sagar, H.J.; Oxbury, J.M. Hippocampal neuron loss in temporal lobe epilepsy: Correlation with early childhood convulsions. Ann. Neurol., 22: 334-340, 1987.

31. Shields, W.D.; Duchowny, M.S.; Holmes, G.L. Surgically remediable syndromes of infancy and early childhood. In: Engel, J. Jr . ed. Surgical Treatment of the Epilepsies. Second Edition, New York, Raven Press, 35 -48, 1993.

32. Sisodiya, S.M.; Free, S.L.; Stevens, J.M.; Fish, D.R.; Shorvon, S.D. Widespread cerebral structural changes in patients with cortical dysgenesis and epilepsy. Brain, 118: 1039-1050, 1995.

33. So, N.; Olivier, A.; Andermann, F.; Gloor, P.; Quesney, L.F. Results of surgical treatment in patients with bitemporal epileptiform abnormalities. Ann. Neurol., 25: 432-439, 1989.

34. Spencer, S.S. Long-term outcome after epilepsy surgery. Epilepsia, 37: 807-813, 1996.

35. Vigevano, F.; Bertini, E.; Boldrini, R. Hemimegalencephaly and intractable epilepsy: Benefits of hemispherectomy. Epilepsia, 30: 833-843, 1989.

36. Williamson, P.D.; French, J.A.; Thadani, V.M.; Kim, J.H.; Novelly, R.A.; Spencer, S.S.; Spencer, D.D.; Mattson, R.H. Characteristics of medial temporal lobe epilepsy: II. Interictal and ictal scalp electroencephalography, neuropsychological testing, neuroimaging, surgical results, and pathology. Ann. Neurol., 34: 781-787, 1993.

\section{Endereço para correspondência:}

Dr. André Palmini

Serviço de Neurologia, Hospital São Lucas da PUCRS Avenida Ipiranga, 6690 90610-000 Porto Alegre, RS 